\title{
Rainstorm Waterlogging Causes and Prevention Measures in Urban Area of Hohhot City
}

\author{
Wentong Li ${ }^{1}$, Zhifen Sun ${ }^{1}$, Narenmandula ${ }^{1}$, Buren ${ }^{1}$, Yuhai Bao ${ }^{2}$, Eerdunmutu Jin ${ }^{2}$
}

${ }^{1}$ Institute of Natural disaster prevention and Control,College of Geographical Science,Inner Mongolia

Normal University,Huhhot 010022,China

${ }^{2}$ Key Laboratory of Remote Sensing \& Geography Information System ,Inner Mongolia Normal

University,Huhhot 010022,China

\section{呼和浩特市城市暴雨内港成因分析及防治措施}

李文通 ${ }^{1}$, 孙志芬 ${ }^{1}$, 那仁满都拉 ${ }^{1}$, 布仁 ${ }^{1}$, 包玉海 ${ }^{2}$, 金额尔德木吐 ${ }^{2}$ ${ }^{1}$ 内蒙古师范大学地理科学学院, 内蒙古师范大学自然灾害防治研究所, 呼和浩特 010022 , 中国 ${ }^{2}$ 内蒙古师范大学遥感与地理信息系统重点实验室, 呼和浩特 010022 , 中国

\begin{abstract}
Analyzing the reasons of waterlogging, the main reasons of waterlogging in Hohhot city includes the change of climate leads to the frequent occurrence of extreme rainstorm, with the change of underlying surface of the city the process of runoff of rainwater also changed the low criteria of diainage systems and the lag of construction. The waterlogging remediation measures for Hohhot City are put forward. To enhance the capability of monitoring and forcast, complilerelated planning, set the concept of risk, strengthen the consciousness of defense, collect and analyze the information of disaster .
\end{abstract}

Keywords: Prevention measures ; Urban waterlogging; Huhhot; Genetic analysis

\section{摘要}

从导致内涝的原因分析, 得出呼和浩特市内涝 的主要成因有: 气候的变化, 极端降水增多、 城市下垫面的变化, 改变了城市的雨水径流过 程、城市排水系统设计标准较低, 建设滞后等。 结合呼和浩特市的实际情况提出了加强监测、 预防, 编制完善相关规划、树立灾害风险观, 增强防范意识, 灾情信息的收集处理与分析的 措施。
关键词: 防治措施; 城市内涝; 呼和浩特; 成 因分析

近年来我国许多城市发生了城市内涝灾 害, “城市看海”现象在各大小城市频频上演。 建设部对 351 个城市 2008-2010 年间的排涝能 力专项调研, $62 \%$ 的城市发生过城市内涝, 39\% 的城市内涝灾害超过 3 次。城市内涝灾情日益 严重, 2012 年 7 月 21 日的北京暴雨内涝导致 79 人死亡, 经济损失高达 166.4 亿元 ${ }^{[1]}$ 。城市 内涝引起了社会各界的广泛关注, 众多专家学 者也对其展开了研究。谢映霞指出我国城市内 涝的原因主要有: 气候变化导致暴雨频繁发生; 河道行洪能力缩减, 雨水调蓄能力减少; 水循 环系统遭到破环; 地表径流发生变化; 原有管 网规划设计标准偏低; 城市规划建设机制不顺 [2]。车伍等提出科学构建 “源头减排-小排水大排水” 系统来实现对雨洪的综合管理 ${ }^{[3]}$; 栗 玉鸿等根据当阳市的地形、河渠、下垫面、管 网等因素综合评估了该市的内涝风险, 并提出 相应的应对措施 ${ }^{[4]}$ 。

呼和浩特市 (以后简称呼市) 是内蒙古自 治区首府, 城市发展迅速, 人口与物质财富高 度集中, 城市内涝带来的不利影响日益凸显。 虽然我国研究城市内涝成因及防治措施的成 果很多, 但是每个城市有其特殊性, 城市内涝 的成因也十分复杂, 故需要根据各地的实际, 分析其城市内涝成因并提出对应措施, 而具体 
Risk Analysis and Crisis Response in Big Data Era (RAC-16)

分析呼市内涝成因的研究较少。本文结合呼市 实际情况, 收集呼市气候、下垫面、城市雨水 管网的相关资料, 分析探讨其发生城市内涝的 原因, 并提出防治措施。为呼市城市规划特别 是排水系统规划建设和相关部门决策提供参 考。

\section{1. 呼市近年城市内港基本概况}

呼市位于北纬 $39^{\circ} 35^{\prime}-41^{\circ} 23^{\prime}$ ，东经 $110^{\circ} 30^{\prime}-112^{\circ} 18^{\prime}$ 之间, 属于温带大陆性 气候。根据 2005-2014 年气象资料的统计, 近 10 年呼市平均降水量为 $340.97 \mathrm{~mm}$, 平均年降 水日为 $66.4 \mathrm{~d}$, 降水主要集中在 6-9 月, 雨量占 全年的 73.04\%; 7 月为降水高峰期, 平均达到 $96.37 \mathrm{~mm}$ ，占全年降水量的 $28.26 \%$ 。

呼市近年来暴雨内涝频发, 灾情严重。 2002 年 7 月 20 日呼市突降暴雨冰雹, 导致城 区部分路面积水，给市民出行造成不便。2008 年 7 月 30 日至 31 日, 由于暴雨, 呼市多处路 面被淹, 积水严重, 呼伦贝尔南路和水上公园 北街的十字路口积水深度达到 50 厘米, 多辆 汽车抛针; 市区部门居民市内被淹, 两间平房 倒塌, 所幸未造成人员伤亡。2012 年 7 月 25 日 0 时至 11 时, 呼市城区累计降水 59.9 厘米, 郊区累计降水 61 厘米。造成市区除公主府立 交外其余的立交桥积水，市区全部 10 座立交 全部关闭; 鄂尔多斯西街、锡林郭勒南路、呼 伦贝尔南路等市区主次干道积水严重; 部分车 辆在水深处熄火, 市区交通趋于瘫疾; 市民出 行受到影响。2013年 6 月 30 日晚至 7 月 1 日, 呼市遭遇暴雨袭击, 哲里木路、护城河南街、 云中路等多处道路积水, 在一个小时内道路最 高积水达到 50 厘米; 多辆汽车水中 “扰针”; 部分店铺被淹, 造成经济损失。2014 年 7 月 6 日起的持续大范围强降水, 导致呼市区多处路 段严重积水，交通不畅，玉泉区钢管厂巷更是 因为地势低洼、排水设施差雨水倒灌形成了一 个 1.5 米深的蓄水区, 导致 300 多户居民被困。

\section{2. 呼市内涝原因分析}

\section{1. 全球气候变化对呼市降水影响分析}

IPCC 第四次评估报告指出由于人类活动 导致全球温室气体增加, 全球气候变暖。与温 度变化呈正相关, 到 21 世纪末中国年降水量 显著增加, 降水有趋于极端化发展趋势, 中雨、
大雨与暴雨频数显著增加 ${ }^{[5]}$ 。图 1 表示东亚地 区四月至九月降水呈增加的趋势, 而强降水作 为城市内涝的主要致灾因子之一, 随着气候变 化强度的增强, 城市内涝灾害风险也在增加。

呼市位于我国东南季风的尾问区, 降水量 400 厘米线附近, 图 2 表示 1965-2014 年降水 变化。西北部东西走向的大青山与东南部南北 走向的蛮汉山半环状环抱着市区所在的土默 特平原。呼市在这种特殊的地理位置、地形和 城市下垫面环境的共同作用下, 呼市的降水呈 现出不稳定、波动大，降水集中于夏季。暴雨 则呈现出频数少、突发性强、局地性强的特点, 呼市暴雨主要以短时强降雨形式为主。近 10 年呼市年降水量呈波动中增加的趋势。近年来 呼市短历时降水 (30 分钟、60 分钟、90 分钟、 120 分钟）降水均值都呈增大趋势, 降水量随 历时时长的增加而增加, 但是增长幅度随历时 时长呈下降趋势。降水强度起伏较大, 但总体 呈增加趋势。强降水频数逐年呈增加趋势, 2011 年以后尤为明显 ${ }^{[6]}$ 。
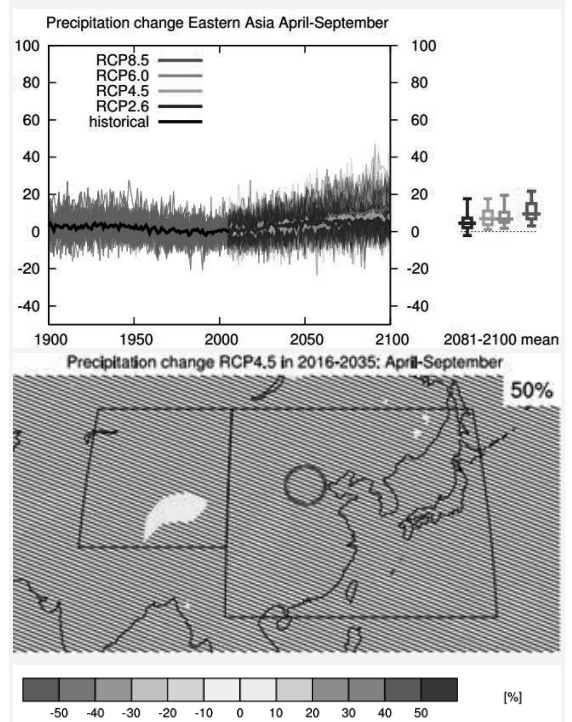

图 1 IPCC 第五次报告对东亚地区降水的分析和预 测 (圆圈表示研究区) 
Risk Analysis and Crisis Response in Big Data Era (RAC-16)

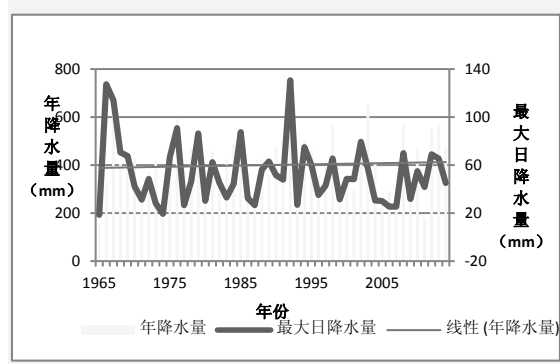

图 2 呼市 1965-2014 年降水变化

综上所述, 受各种因素影响, 呼市近年暴 雨频数和强度都呈增加趋势, 从而导致城市内 涝频发。

2.2.城市下垫面变化对雨水径流过程影响分析

随着城市化的快速推进, 呼市城市规模不 断扩大, 城市建成区面积 2003 年为 $120 \mathrm{~km}^{2}$, 2013 年则达到了 $230 \mathrm{~km}^{2[7-8]}$ 。随着城市建成区 的不断扩展, 城区周边大量土地的利用方式从 农业用地转为城市建设用地, 意味着不透水面 的扩展。径流系数不断增加, 雨水径流时间缩 短, 总的汇水面积增加, 需要排除的总雨水量 不断增加。

受气候、地理位置等因素的影响呼市市内 水体水面面积、容纳量本来就较低, 由于城市 的开发, 部分水面、池塘、河道被侵占填埋。 建成区绿地覆盖率 2013 年为 36.5\%低于同期 的国家平均的 $39.7 \%{ }^{[9]}$; 城市水体、绿地对雨 水的调蓄能力不足。

一方面, 城市需要排除的雨水总量不断增 加、径流时间不断缩短。另一方面城市水体的 破坏、绿地率较低, 对雨水的调蓄能力日益减 弱。对城市雨水管网的排水能力提出更高的要 求, 也加剧了城市内涝灾害的风险。

\section{3.城市雨水管网系统排水能力分析}

呼市采用雨污分流的排水体制。雨水管网 历史欠账较多, 尚未完善。设计标准较低, 2011 年以前设计重现期仅为 0.33-1 年, 《呼和浩特 市城市排水（雨水）综合规划(2012-2020)》规 划干线设计重现期为 1-2 年, 重要地区为 2-5 年, 且并未明确内涝防治标准。

城市雨水管网建设滞后于城市发展。城市 雨水管网密度较低, 部分地区甚至未在管网覆 盖范围之内。截至到 2014 年呼市雨水管道为 $754 \mathrm{~km}$, 建成区雨水管网密度仅为 $3.8 \mathrm{~km} / \mathrm{km}^{2}$
远低于同期国家直辖市和省会平均水平的 $10.01 \mathrm{~km} / \mathrm{km}^{2}$ (见图 3)。管网管径较小，不能 满足城市当前的排水需求, 布局十分凌乱, 易 导致接错管道。

雨水管网及设施管理落后, 部分设施老化, 或者维护保养不好未能发挥全部作用。截至到 2016 年, 呼市共有 11 个排水葲站, 其中 10 个因为水洜老化、供电负荷不足、管理设施不 完善等原因导致排水能力不足。

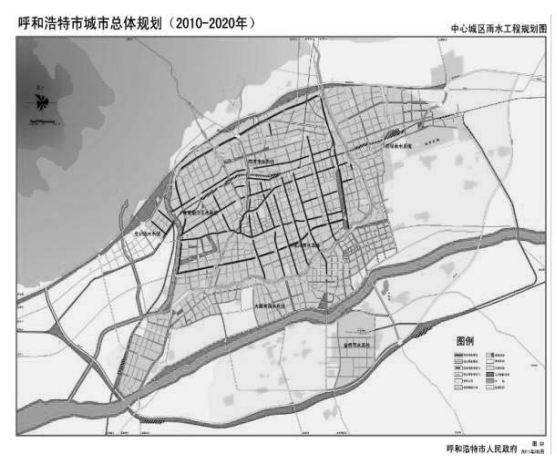

图 3 呼市城市总体规划（2010-2020）中雨水工程 规划图

\section{3.呼市城市内港防治措施}

气候的变化、极端降水事件频发, 内涝致 灾因子强度增大。城市建设的不合理和城市中 不断聚集的人、财、物导致了承灾体的脆弱。 使呼市内涝灾情日益严重。必须采取必要的措 施来提升城市的安全, 以下是针对呼市城市内 涝产生原因, 提出的一些措施。

\section{1. 建立完善城市内涝监测、预警系统}

“预防为主、防治结合、防救结合” 是我 国的防灾减灾方针, 通过科学的监测和预警能 够有效降低灾害的不利影响。我国各地针对城 市内涝预警系统展开了全面的研究, 许多成熟 的研究成果运用于实践, 在城市内涝灾害的防 灾减灾领域中发挥了重要作用。其中以天津市 气象科学研究所与中国水利水电研究院共同 研制的城市暴雨内涝仿真模型在内涝预警系 统的建设中运用最为广泛 ${ }^{[13]}$ 。呼市气象局也以 此模型为基础, 结合本市的地形地貌、排水设 施等实际情况构建了本市的城市内涝预警系 统 ${ }^{[14]}$ 。但是针对降水及其径流过程的实际过程 监测研究及实践较少, 后续需要加强对包括雨 水管网流量监测在内的降水径流过程的实时 
动态监测, 从而构建一个完整的预测-监测系 统, 提高灾害预防的准确性, 合理配置宝贵的 防灾资源。

另一方面, 需要完善预警信息发布体系。 随着信息技术的快速发展, 出现许多新的通信 方式, 如微博、微信等, 新的通信方式能够将 信息能将信息快速、大范围的传播。用这些新 技术来完善传统的电视、手机信息等信息发布 体系。将监测预警信息及时传达给受灾群众和 相关部门, 让受灾区域能够做好相应的防灾准 备, 降低灾害损失。

\section{2.编制完善相关规划，提升城市雨水管控能} 力

针对日益严重的城市内涝灾情, 国务院办 公厅在 2013 年 4 月发布了《国务院办公厅关 于做好城市排水防涝设施建设工作的通知》 (国办发[2013]23 号) 文件, 提出了对城市内 涝防治的要求和一系列措施。建设部也在 2013 年 6 月印发了《城市排水 (雨水) 防涝综合规 划编制大纲》（以下简称大纲）以指导各地的 《城市排水 (雨水) 防涝综合规划》 (以下简 称排水规划) 的编制。大纲包括: 规划背景与 现状概况, 城市排水防涝能力与内涝风险评估, 内涝风险评估与区划, 城市雨水径流控制欲资 源化利用, 城市排水 (雨水) 管网系统规划, 城市防涝系统规划, 近期建设规划, 管理规划, 保障措施及相关附件共 10 部分内容并对这些 内容作了说明。依据此纲要编制的排水规划已 经是一个科学完善雨水管控方案。呼市应该尽 快完成符合本市实际情况的规划, 明确城市内 涝防治标准, 设计重现期至少应达到《大纲》 规定的省会城市不低于 50 年, 为城市排水系 统建设、运营管理和防涝减灾提供依据和支持。

推进城市排水规划与城市总体规划及绿 地系统规划、竖向规划等专项规划的衔接, 加 强各项规划间的协作。将城市布局正在安全的 地块上, 划定蓝线、绿线, 加强对市区水体和 绿化的保护。转变城市开发模式, 采用 $\operatorname{LID}$ (低 影响开发)等新的开发模式。规划师应该更新 规划理念使规划设计更趋生态, 充分利用自然 地理条件构建城市海绵体。

要加强对规划实施的监管, 让规划落到实 处, 再好的规划不能落实的话也只是一纸空谈。 呼市城区原规划与建设有满都海公园调蓄人
工湖、青城公园调蓄人工湖以及零星的调蓄坑 塘, 分别担负呼市市区不同片区蓄洪、防涝工 作。由于雨污分流不彻底, 两大调蓄人工湖与 城市排水(雨水)联通管已经废弃使用, 失去了 原有的蓄洪、防涝功能。另一方面, 政府决策 者要转变过去 “重地上、轻地下”的观念, 实 践已经证明这种观念市错误的, 导致了现在众 多的城市问题, 也不利于城市未来长远的建设 和发展。

\section{3.树立灾害风险观，增强防范意识}

多年来, 我国城市防灾问题未得到重视, 而城市内涝灾害又是在近年才凸现, 公众安全 意识淡薄, 缺乏最基本的识灾、防灾的能力和 自我保护的意识。缺乏必要的防灾意识和知识 是我国存在的普遍问题，只有不到 $4 \%$ 的城市 居民做了基本防灾准备 ${ }^{[16]}$ 。在一则报道呼市的 新闻中, 马路上的积水已经淹没半个车身, 仍 有群众不顾安危试图骑车穿过积水区。相关部 门应该投入经费, 通过电视、网络、防灾演习、 防灾知识讲座等形式向公众传播防内涝灾害 的相关知识, 增强公众的识灾、防灾意识, 提 升防灾能力。

作为决策者的政府官员更要树立风险观， 因为其所做决策关系着相关区域的安全, 尽量 在决策时选择能够降低城市内涝风险的方案。

\section{4.灾情信息的收集整理与分析}

呼市各相关部门在灾后缺乏详细的灾情 信息记录, 灾害发生时受灾范围、灾情的统计 以现在的手段是完全能够实现的。今后需要加 强对灾情信息的收集与整理和分析研究, 找出 发生内涝的具体原因, 为以后的防灾和城市建 设提供参考。

\section{4.结语}

由于呼城市排水系统历史欠账较多, 近期 建设滞后, 需要相当长的时间建设和完善, 城 市内涝会在今后相当长的时间发生。在分析呼 市城市内涝的成因基础上, 提出了内涝应对措 施, 加强城市排水系统建设, 提升雨水管控能 力; 完善防灾非工程措施; 共同构建完善的呼 市内涝防灾减灾体系。降低内涝灾害带来的损 失, 确保城市的安全。

由于资料收集等方面的限制, 本文未能分 析导致呼市内涝的各致灾因子的强度。另外由 


\section{Risk Analysis and Crisis Response in Big Data Era (RAC-16)}

于城市内涝成因十分复杂, 是多种因素综合影 响下的结果, 难免会有未考虑到的影响因素。 后续应该在全面的资料收集和细致的分析的 基础之上确定导致呼市内涝的各致灾因子强 度以更好地指导城市房子和建设。

\section{致谢}

本研究得到了国家自然科学基金项目（

41461101），内蒙古自治区应用技术研发资金 计划项目 (201502095), 内蒙古师范大学科 研究项目 (ZRYB1005) 的资助。

*通信作者: 那仁满都拉男, 博士, 副教授, 1974 年生, nm2050@163. com

\section{参考文献:}

[1] 新华网. 2008年至 2010 年我国 351 个城市 发生过内涝. 2012-07-24. http://news.xin huanet.com/politics/2012-07/24/c_1234580 67.htm.

[2] 谢映霞. 从城市内涝灾害频发看排水规划 的发展趋势. 城市规划, 2013，(2): 4550 .

[3] 车伍, 杨正, 赵杨, 等. 中国城市内涝防 治与大小排水系统分析. 中国给水排水, 2013, 29 (16): 13-19.

[4] Y.H. Li, L. Shi, J.H. Wang, Y.J. Hu, J. Fan. Pluvial Flooding Risk Analysis and the Solutions to Risk Mitigation for D angyang City in China. Journal of Risk Analysis and Crisis Response, 2015, 5 (2): 107-119.

[5] 陈活泼. CMIP5 模式对 21 世纪末中国极 端降水变化的预估. 科学通报, 2013, (5 8): 743-752.

[6] 苏利军. 呼和浩特短历时强降水强度变化 特征分析. 内蒙古林业科技, 2015, 41(3): 53-56.

[7] 呼和浩特统计局. 呼和浩特经济统计年鉴 2005. 2005-07. http://www.huhhot.gov.cn/ hhhttjj/nj/05nj/05nj3.htm.

[8]呼和浩特统计局. 呼和浩特经济统计年鉴 2
014.2014-09. http://www.huhhot.gov.cn/hh httjj/nj/2014\%C4\%EA\%BC\%F8/gb2.html.

[9] 住房和城乡建设部. 2013 年城乡建设统计 年鉴. 2016-02-02. http://www.mohurd.go v.cn/xytj/tjzljsxytjgb/index.html.

[10] 赵艳丽. 呼和浩特暴雨成因诊断分析 [D]. 兰州: 兰州大学. 2008 .

[11] 程晓陶. 城市型水灾害及其综合治水方 略. 灾害学, 2010, 25(S0):10-15.

[12] 任毅, 周倩倩, 李冬梅, 等. 呼和浩特市 大排水系统的构建规划与评估研究. 人 民珠江，2015，36 (4): 25-28.

[13] 仇劲卫, 李娜, 程晓陶, 等. 天津市城区 暴雨沥涝仿真模拟系统. 水利学报, 2000, (11): 34-42.

[14] 司瑶冰, 王爱英, 谷新坡, 等. 呼和浩特 城市内涝预报系统研究. 内蒙古气象, 20 07, (4): 4-6.

[15] 冯杰, 黄国如, 张灵敏, 等. 海口市城市 暴雨内涝成因及防治措施. 人民珠江， 2 015, 36 (5): 71-74.

[16] 中国扶贫基金会. 中国公众防灾意识与 减灾知识基础调查报告[R]. 2015. 